\title{
The Influence of Disease Severity on Health Related Quality of Life of Patients with COPD
}

\author{
RSP Fernando ${ }^{\mathrm{a}, *}$, RTG Wickramanayake ${ }^{\mathrm{a}}$, GGN Dulanjanie ${ }^{\mathrm{a}}$, HDT Perera ${ }^{\mathrm{a}}$, II \\ Vidanagamachchi ${ }^{\mathrm{a}}$, MDC Silva $^{\mathrm{a}}$, RANK Wijesinghe $^{\mathrm{b}}$
}

*sithijapriyankara@kdu.ac.lk

${ }^{a}$ Department of Physiotherapy, Faculty of Allied Health Sciences, General Sir John Kothelawala Defence University, Werahera, 10290, Sri Lanka

${ }^{b}$ Faculty of Medicine, General Sir John Kothelawala Defence University, Rathmalana, 10390, Sri Lanka

\begin{abstract}
Chronic Obstructive Pulmonary Disease (COPD) is one of the major global health issues becoming of the leading cause of morbidity and mortality around the world. This study was undertaken to evaluate the impact of disease severity on Health Related Quality of Life (HRQoL) and the influence of factors affecting on it.

A total of 77 patients who had been medically diagnosed as COPD by a consultant physician were recruited according to systematic sampling method at National Hospital for Respiratory Diseases, Welisara. St. George's Respiratory Questionnaire was used to assess HRQoL and lung function parameters and socio demographic data was collected. Disease severity of COPD patients was categorized according to GOLD guidelines. Data was analyzed using SPSS version 23.0.
\end{abstract}

The mean age of 77 participants was 59.39 \pm 7.28 ranged from 40-70 years and majority of them were males $(n=70$, 90.9\%). Patients fallen under GOLD stage I was not observed within the sample. There was no statistically significant difference in the SGRQ scores between the severity groups $(\mathrm{p}=0.347)$. Significant weak negative correlations were found between impact domain and $\mathrm{FEV}_{1}(\mathrm{r}=-0.239, \mathrm{p}=0.036)$ and $\mathrm{FEV}_{1}$ predicted $\%(\mathrm{r}=-0.223, \mathrm{p}=0.049)$. Further significant negative correlation was found between $\mathrm{FEV}_{1}$ predicted $\%$ and symptom domain $(r=-0.202 \mathrm{p}=0.039)$

The influence of disease severity on HRQoL can be vary once the disease has progressed in COPD patient regardless of gender, age, and smoking habits. The impact of comorbidities should be observed to identify the influence of them on HRQoL. 


\section{Introduction}

Chronic Obstructive Pulmonary Disease (COPD) is known as a progressive lung disease that causes breathlessness and predisposes to exacerbations and serious illnesses [1]. The Global Initiative for Chronic Obstructive Lung Disease (GOLD), 2017 [2] report defines COPD as a common, preventable and treatable disease, which is characterized by persistent airflow limitation usually progressive and worsens the daily activities of such persons.

Out of four main non communicable diseases, COPD adversely impact the health status of the Sri Lankan population [3]. Sri Lanka has shown an overall prevalence of $10.5 \%$ of COPD patients, where the urban and rural prevalence rates are $6.4 \%$ and $4.1 \%$ correspondingly [4]. COPD causes a significant economic burden to the country. Hence it is very important to identify patients with higher risk of exacerbations of COPD in order to take precautionary measures.

Quality of Life (QoL) is an individual perception of satisfaction of their life in relation to their expectations. Health related quality of life (HRQoL) refers to perception of impact of health on individual's QoL [5]. Most of the patients with chronic diseases greatly value their quality of life rather than their survival [6]. Various questionnaires and tools have been used to quantify the impact of the disease upon their daily activities from the COPD patient's point of view. St. George's Respiratory Questionnaire (SGRQ) is a disease specific tool to self-report the level of HRQoL [7].

Therefore, the aim of this study was to evaluate the HRQoL of Sri Lankan COPD patients based on their disease severity to concrete the prevailing data on COPD. Further the association between HRQoL and forced vital capacity as a percentage of predicted normal values (FVC \% pred.) was evaluated.

The lack of information regarding the impairment of HRQoL of COPD patients with the disease progression might be the possible reason for the less concern on HRQoL during patient management [8]. Similarly, the literature regarding HRQoL of Sri Lankan COPD patients are limited and its consideration and application in patient management remains unclear.

\section{Methodology}

\subsection{Study Sample}

A total of 77 patients who had been medically diagnosed as COPD by a consultant physician were recruited according to systematic sampling method. All the even numbered patients were selected using the registry in the COPD clinic on each day, which was held once a fortnight during August 2017 - October 2017 at the NHRD, Welisara, Sri Lanka. Patients who were diagnosed with COPD for more than 5 years and aged between 35 years to 60 years were included. Patients with other disabling or severe disease and/or coexistence of other causes of impaired pulmonary functions and patients with history of COPD for less than 05 years were excluded.

After the initial assessment, the patients who falls in the inclusion criteria were administered by an investigator and the socio demographic data and HRQoL questionnaire was completed unaided by the participants. 


\subsection{St. George's Respiratory Questionnaire}

St. George's Respiratory Questionnaire (SGRQ) is a widely used and best known disease specific HRQoL questionnaire for respiratory diseases (jones et al.). Fifty items having empirically derived weights were subdivided in to three domains including symptom, activity, and impact. A score was calculated for each domain and a total score ranging from 0-100 were obtained by calculating all three domains. Lower scores indicate a better HRQoL with no impairment and worst possible in higher scores.

\subsection{Spirometry measurements}

The spirometry test was performed using the calibrated digital, spirometer at NHRD, which was validated before the test. The machine directly provided the graphs and accurate FEV1 values and the FEV1\% pred values in the display according to the age, height, weight, and gender.

\subsection{Data Analysis}

Descriptive statistics were conducted for all the analyzed variables whereas all showed a normal distribution. Nonparametric Spearman correlation coefficient analysis was conducted to evaluate the relationship between HRQoL measures and spirometric measurements. Statistical analysis was performed using an Analysis of Covariance (ANCOVA) model with SQRQ scores (Symptom domain, Activity domain, Impact domain and Total score) as a dependent variable. GOLD classification of COPD severity was used as the factor in the analysis. Age, gender, and smoking history were used as covariates. All variables with $\mathrm{p}<$ 0.05 were considered as at $95 \%$ confidence interval. Data was analyzed by SPSS version, 23.0.

\section{Results}

The mean age of 77 participants was 59.39 7 7.28 ranged from 40-70 years. Majority of the participants in the study group were males $(n=70,90.9 \%)$. None of the female patients were found on GOLD stage IV. Patients fallen under GOLD stage I was not observed within the sample. In the six age groups (the lowest $<45$ and the highest $>66$ years) $50(64.9 \%)$ patients were smokers and all the smokers were males.

Table 1. The baseline demographic data

\begin{tabular}{lcccc}
\hline $\begin{array}{l}\text { Characteristic } \\
\text { Mean (SD) }\end{array}$ & $\begin{array}{c}\text { Total } \\
(77)\end{array}$ & $\begin{array}{c}\text { Gold stage II } \\
(37)\end{array}$ & $\begin{array}{c}\text { Gold stage III } \\
(34)\end{array}$ & $\begin{array}{c}\text { Gold stage IV } \\
(6)\end{array}$ \\
\hline Age & $59.39(7.28)$ & $59.76(7.31)$ & $59.53(6.99)$ & $56.33(9.22)$ \\
Gender & & & & \\
$\quad$ Male & 70 & 33 & 31 & 6 \\
$\quad$ Female & 7 & 4 & 3 & 0 \\
Smoking status & & & & \\
$\quad$ Non smoking & 27 & 16 & 9 & 2 \\
$\quad$ Smoking & 50 & 21 & 25 & 4 \\
Years & $7.82(4.32)$ & $7.73(4.31)$ & $7.85(4.18)$ & $8.17(5.88)$ \\
\hline
\end{tabular}




\subsection{HRQoL in relation to COPD severity according to GOLD}

There was no statistically significant difference in the SGRQ scores between the severity groups $(\mathrm{p}=0.347)$.

The severity grades affected the level of SGRQ Total as follows: stage II: 65.32, stage III: 69.67 and stage IV: 71.03. (Table 2)

Table 2. Distribution of SGRQ domains and Total by Global Initiative for Chronic Obstructive Lung Disease (GOLD) stages.

\begin{tabular}{lccccc}
\hline Characteristic & $\begin{array}{c}\text { Total } \\
(77)\end{array}$ & $\begin{array}{c}\text { Gold stage II } \\
(37)\end{array}$ & $\begin{array}{c}\text { Gold stage III } \\
(34)\end{array}$ & $\begin{array}{c}\text { Gold stage IV } \\
(6)\end{array}$ & p value \\
\hline SGRQ Symptom & $68.11(20.92)$ & $63.67(23.86)$ & $72.46(16.77)$ & $70.76(20.37)$ & 0.200 \\
SGRQ Activity & $82.06(15.74)$ & $81.11(17.33)$ & $82.32(14.95)$ & $86.42(9.88)$ & 0.744 \\
SGRQ Impact & $59.00(15.75)$ & $56.51(16.13)$ & $61.19(15.81)$ & $61.98(12.68)$ & 0.413 \\
SGRQ Total & $67.69(13.80)$ & $65.33(14.10)$ & $69.67(13.68)$ & $71.03(11.95)$ & 0.347 \\
\hline
\end{tabular}

Comparatively GOLD stage IV patients had highest total SGRQ interpreting the worst HRQoL of them. Relatively the activity domain scored higher values in all the stages than other domains showing the impairment of activity level among patients in the study.

3.2 Influence of age, gender, smoking status and duration of the disease

\subsubsection{Age}

The scores of Total SGRQ for age groups varied from 61.77 ( $<45$ years) to 71.12 (> 66 years) and they were not statistically significant $(\mathrm{p}=0.430)$ (Table 3$)$. But both activity and impact domains were worst in the 4650 age group than other groups but in contrast it has the lowest score in symptom domain.

Table 3. The SGRQ scores according to the age categories. Age: years, Mean (SD)

\begin{tabular}{lllll}
\hline $\begin{array}{l}\text { Age group } \\
\text { (Years) }(\mathrm{n})\end{array}$ & Symptom Domain & Activity Domain & Impact Domain & SGRQ Total \\
\hline$<45(5)$ & $67.41(21.11)$ & $79.09(13.18)$ & $49.54(21.07)$ & $61.77(17.10)$ \\
$46-50(6)$ & $62.06(18.19)$ & $86.40(08.50)$ & $66.83(13.15)$ & $71.76(11.08)$ \\
$51-55(10)$ & $68.77(20.66)$ & $81.39(16.66)$ & $57.49(14.06)$ & $66.82(12.79)$ \\
$56-60(15)$ & $66.34(26.08)$ & $84.49(18.94)$ & $60.71(16.80)$ & $69.01(16.66)$ \\
$61-65(19)$ & $67.74(17.97)$ & $76.26(17.21)$ & $54.11(16.80)$ & $63.32(14.63)$ \\
$66>(22)$ & $71.12(22.00)$ & $85.18(13.46)$ & $62.76(13.36)$ & $71.12(10.94)$ \\
\hline
\end{tabular}




\subsubsection{Gender}

Table 4. The score percentage distribution according to the gender in each component of HRQoL in St George's Respiratory Questionnaire

\begin{tabular}{llllll}
\hline & & Symptom Domain & Activity Domain & Impact Domain & SGRQ Total \\
\hline Male & Mean (SD) & $66.6(21.17)$ & $82.20(15.04)$ & $58.00(15.52)$ & $66.97(13.62)$ \\
& Range & $(00-97.05)$ & $(37.58-100)$ & $(27.44-88.66)$ & $(34.24-92.50)$ \\
\multirow{2}{*}{ Female } & Mean (SD) & $82.36(11.37)$ & $80.62(23.11)$ & $68.97(15.63)$ & $74.92(14.49)$ \\
& Range & $(60.95-97.07)$ & $(44.77-100)$ & $(53.21-94.56)$ & $(51.99-94.18)$ \\
& & & & & \\
\hline
\end{tabular}

In the symptom component, the highest mean score percentages were encountered by females $(82.36 \pm$ 11.37). In males mean score percentages were ranged from no impairment of HRQoL (0.0\%) to $97.05 \%$. The highest mean score percentage among three components was recorded in the activity component by obtaining the maximum amount of impairment (Maximum score percentage $=100 \%$ ) in HRQoL in both genders. There was significant difference between the mean score percentages among male and female groups in both symptom ( $\mathrm{p}=0.05)$ and impact $(\mathrm{p}=0.48)$ domains. As a whole, female's HRQoL was mostly affected as they had obtained the highest mean total score percentage of $74.92 \% \pm 14.49$, where males showed only $66.97 \% \pm$ 13.62 .

\subsubsection{Smoking history}

Table 5. The variation of SGRQ scores among Non-smokers vs Smokers.

\begin{tabular}{llccc}
\hline & Symptom Domain & Activity Domain & Impact Domain & SGRQ Total \\
\hline Non-smoking (27) & $71.16(24.57)$ & $80.38(16.67)$ & $58.72(17.74)$ & $67.57(15.69)$ \\
Smoking (50) & $66.45(18.71)$ & $82.96(15.30)$ & $59.15(14.75)$ & $67.75(12.81)$ \\
\hline
\end{tabular}

Both mean scores of SGRQ total were same and no significant difference was found among them $(\mathrm{p}=0.965)$. Non-significant differences were observed between smoking and non-smoking with in each domain (Table 5). 


\subsubsection{Duration}

The scores of Total SGRQ for age groups varied from $65.66(5-7$ years, $n=52)$ to 71.44 (> 11 years, $n=11)$ and they were not statistically significant $(\mathrm{p}=0.584)$.

\subsubsection{Correlation between FEV1\% and Total SQRQ scores}

Table 6 illustrates significant weak negative correlations found between impact domain and $\mathrm{FEV}_{1}(\mathrm{r}=-0.239$, $\mathrm{p}=0.036)$ and $\mathrm{FEV}_{1}$ predicted $\%(\mathrm{r}=-0.223, \mathrm{p}=0.049)$. Further significant negative correlation was found between $\mathrm{FEV}_{1}$ predicted $\%$ and symptom domain $(\mathrm{r}=-0.202 \mathrm{p}=0.039)$

Table 6. The correlation between SGRQ scores and lung function parameters. ( ${ }^{*} p<0.05$ )

\begin{tabular}{lcccc}
\hline & \multicolumn{3}{c}{ Health Related Quality of Life (SGRQ Scores) } \\
\cline { 2 - 5 } & Symptom & Activity & Impact & Total \\
\hline FEV $_{1}$ & $\mathrm{r}=-0.171$ & $\mathrm{r}=-0.028$ & $\mathbf{r}=\mathbf{- \mathbf { 0 . 2 3 9 } *}$ & $\mathrm{r}=-0.179$ \\
& $(\mathrm{p}=0.137)$ & $(\mathrm{p}=0.810)$ & $(\mathbf{p}=\mathbf{0 . 0 3 6})$ & $(\mathrm{p}=0.118)$ \\
& & & & \\
FEV $_{1}$ predicted \% & $\mathbf{r}=\mathbf{- 0 . 2 0 2 *}$ & $\mathrm{r}=-0.003$ & $\mathbf{r}=\mathbf{- \mathbf { 0 . 2 2 3 } *}$ & $\mathrm{r}=-0.113$ \\
& $(\mathbf{p}=\mathbf{0 . 0 3 9})$ & $(\mathrm{p}=0.982)$ & $(\mathbf{p}=\mathbf{0 . 0 4 9})$ & $(\mathrm{p}=0.329)$ \\
\hline
\end{tabular}

\section{Discussion}

The findings of the present study conclude that the disease severity based on $\mathrm{FEV}_{1}$ has no significant effect on HRQoL of the participants, which is in par with the findings of Stahl et al. (2001) [8]. In contrast, Stahl et al. (2005) confirms that disease severity classified according to $\mathrm{FEV}_{1}$ influences to the HRQoL among COPD patients [9]. But the total SGRQ score of the stage IV of above study was less than the SGRQ total score of stage II of our study. This confirms that it is insufficient to conclude the severity of COPD patient based only on GOLD classification. The study done by Medinas et al. (2008) reported that disease severity strongly influences the HRQoL of COPD patients [10]. The need of different severity classifications should be highlighted to future researchers on this area based on Sri Lankan COPD patients.

According to the findings of our present study, female participants had worse HRQoL than males confirming the significant difference between males within symptom and impact domains. This confirms the suggestions 
made by Juniper et al. (1992) who states that sensitive changes of HRQoL can be expected from female population with COPD [11]. But in contrast, a recent study done by Mahesh et al. (2018) found that gender has no significant influence on QoL which tallies with the findings of the present study [12]. But it should be comprehensively studied, how gender effects on HRQoL of Sri Lankan COPD patients.

Though smoking habits among females are rising in Western countries, the usage of tobacco and smoking in Sri Lankan female population still believed to be less. This might be the reason for less no female participation in our study. COPD also may be an outcome of higher exposure to indoor air pollution such as biomass fuel used for cooking, passive smoking and heating in low-income countries [13]. Furthermore, the accessibility to free health services irrespective of gender would help women to address their health care needs.

The various authors have reported the association between HRQoL and smoking status. In this study smoking did not influence the HRQoL similar to the findings of Stahl et al. (2005) [9]. Both smokers and non-smokers has similar deterioration of HRQoL this is supported by the explanation given by Wijnhoven et al. (2003) as less severe stage COPD patients do not quite smoking [14]. However, it is difficult to predict the effect of age, gender and smoking history on HRQoL once the patient is diagnosed with COPD Stahl et al. (2005) concluding the findings of this study [9].

Several studies Stahl et al. (2001) have reported the weak correlation between lung function parameters and the HRQoL similar to the findings of our study [8]. The correlation found among FEV1 and FEV1 predicted $\%$ and impact domain of the SGRQ scores indicates the influence of psychological status on HRQoL measures. Further, the self-perception on the patient's condition might be the reason behind the correlation between the FEVI predicted \% and the symptom score of the patient.

\section{Conclusions and Recommendations}

The findings of our present study shows that there is no correlation between disease severity and HRQoL COPD patients. Less number of patients with very severe stage of COPD was one of the limitations of this study. But the ANCOVA analysis compensated the skew distribution. Another limitation was the absence of patients with mild severity suggesting the ignorance of the disease condition when it seems less severe and the discontinuation of management. The impact of comorbidities should be observed in order to identify the influence of them on HRQoL. Further the inclusion of female patients and the effects of the parameters should be evaluated in extensively. 


\section{Acknowledgements}

Our sincere gratitude should go to the staff of Physiotherapy Department and the all the consultants of respiratory clinics of NHRD for the immense support to conduct the study. Further special thank should goes to Dr. SP Senanayake, Senior Lecturer, Department of Basic Sciences, FAHS, KDU for giving valuable comments for the study.

\section{References}

1. World Health Organization: Chronic obstructive pulmonary disease. [http://www.who.int/mediacentre/factsheets/fs315/en/index.html], Accessed February 10, 2021.

2. Global Initiative for Chronic Obstructive Lung Disease: Global strategy for diagnosis, management, and prevention of COPD (updated 2010). [http://www.goldcopd.com/Guidelineitem.asp?11=2\&12=1\&intId=1116]

3. WHO Noncommunicable diseases: campaign for action - meeting the NCD targets: Sri Lanka profile. Geneva: World Health Organization, 2017. Available from: http://www.who.int/beat-ncds/countries/sri-lanka/en/.

4. Amarasiri, L., Gunasinghe, W., Sadikeen, A., Fernando, A., Madegedara, D., Wickramasinghe, R. Gunasekera, K., 2017. The prevalence of Chronic Obstructive Pulmonary Disease (COPD) in Sri Lanka: outcome of the BOLD study, European Respiratory Journal, 50 (suppl 61), PA1212.

5. WHOQOL Group, 1998. Development of the World Health Organization WHOQOL-BREF quality of life assessment. Psychological Medicine 28(3). p. 551-558.

6. Swigris, JJ., Kuschner, WG., Jacobs, SS., Wilson, SR., Gould, MK., 2005. Health related quality of life in patients with idiopathic pulmonary fibrosis: a systematic review, Thorax 60, p. 588-594.

7. Jones, PW., Quirk, FH., Baveystock, CM., 1991. The St George's respiratory questionnaire, Resp Med 85 (Suppl. 2 ), p. $25-31$.

8. Stahl, E., Wadbo, M., Bengtsson, T., Strom, K., Lofdahl, CG., 2001. Health-related quality of life, symptoms, exercise capacity and lung function during treatment for moderate to severe COPD. Journal of Outcomes Research. (5), p. 11-24.

9. Ståhl, E., Lindberg, A., Jansson, SA., Rönmark, E., Svensson, K., Andersson, F., Löfdahl, CG., Lundbäck, B., 2005. Health related quality of life is related to COPD disease severity, Health and quality of life outcomes 3, p. 56 .

10. Medinas-Amorós, M., Alorda, C., Renom, F., Rubí, M., Centeno, MJ., Ferrer, V., Gorriz, T., Mas-Tous, C., Ramis, F., 2008. Quality of life in patients with chronic obstructive pulmonary disease: the predictive validity of the BODE index, Chron Respir Dis 5, p. 7-11.

11. Juniper, EF., Guyatt, GH., Epstein, RS., Ferrie, PJ., Jaeschke, R., Hiller, TK., 1992. Evaluation of impairment of health related quality of life in asthma: development of a questionnaire for use in clinical trials, Thorax. 47, p. 76-83.

12. Mahesh, B., Gunathunga, W., Jayasinghe, S., Arnold, M., Croos, V., de Silva, S., 2018. Quality of life and its associated factors among patients with COPD before and after an exacerbation in Sri Lanka, Journal of the College of Community Physicians of Sri Lanka 24(2), p. 66-75.

13. Kurmi, OP., Lam, KBH., Ayres, JG., 2012. Indoor air pollution and the lung in low-and medium-incom countries, European Respiratory Journal 40(1), p. 239-254.

14. Wijnhoven, HA., Kriegsman, DM., Hesselink, AE., de Haan, M., Schellevis, FG., 2003. The influence of co-morbidity on healthrelated quality of life in asthma and COPD patients, Respir Med. 97(5), p. 468-475. 